The real future of good general and geriatric practice lies in prevention. In the matter of home accidents to the elderly, at least, there is the greatest possible opportunity for simple, practical countermeasures to reduce morbidity and mortality, while at the same time encouraging patients to greater independence.

\section{Appendix}

Below are given the sources of information about aids for the disabled, the elderly, and those at risk from accidents in the home:

1. Equipment for the Disabled, vols. 1-4. Published by the National Fund for Research into Poliomyelitis and other Crippling Diseases, Vincent House, Vincent Square, London S.W.1. Looseleaf volumes, profusely illustrated, some with commercial sources quoted, others with examples of adaptation of common objects.

2. Gadget Leaflets. Published by the National Association for the Paralysed, 1 York Street, Baker Street, London W.1. Lists of aids, with some line drawings, and certain commercial sources stated. (N.B. : Cooker safeguard well illustrated.)
3. Practical Aids for the Disabled. Published by the British Red Cross Society, 14 Grosvenor Crescent, London S.W.1. Illustrated with line drawings of aids, mostly of the do-it-yourself variety.

4. Everyday Aids for the Disabled. Published by the West Sussex Association for the Care of Cripples. Oriel House, County Hall, Chichester. Simple do-it-yourself type aids; illustrated line drawings.

5. Aids for the Disabled. Price List H/4. This is a pamphlet with a list of commercial suppliers at the end, and is published by the Home Department of the British Red Cross, 14 Grosvenor Crescent, London S.W.1. Dated January 1965.

REFERENCES

Boucher, C. A. (1959). Geriatrics, 14, 293.

- (1966). Communication to the 7th International Congress of Gerontology, Vienna. In press.

Bull, J. P., and Squire, J. R. (1949). Ann. Surg., 130, 160.

Sheldon, J. H. (1960). Brit. med. F., 2, 1685.

- (1966). In Medicine in Old Age, edited by J. N. Agate, p. 199. Pitman Medical Publishing, London.

\title{
Poisoning in the Home by Medicaments
}

\author{
HENRY MATTHEW,* M.B., CH.B., F.R.C.P.ED.
}

Brit. med. F., 1966, 2, 788-790

Accident prevention is an important responsibility of all medical practitioners. Perhaps their greatest contribution should be the prevention of poisoning in the home from the ingestion of medicaments. In adults acute poisoning accounts for approximately $10 \%$ of all medical admissions ; in children about $3 \%$ of all medical admissions are due to accidental poisoning. In certain cities more children die each year from poisoning than from the following communicable diseases combined: measles, rubella, poliomyelitis, tuberculosis, rheumatic fever, scarlet fever, and streptococcal infections. Backett (1965) has shown that domestic accidents are now an important cause of death; in developed countries mortality at all ages from domestic accidents is twice that from tuberculosis. Of these domestic accidents a proportion are due to poisoning and gassing. The percentage of fatal accidents (Fig. 1) due to poisoning and gassing in the various countries for which statistics are available shows that Scotland is in the unenviable position of having the highest incidence of death from these causes. Part of the explanation is that death certification in Scotland is more lax, and deaths due to suicide are often charitably designated accidental. In support of this, suicide is commoner in the other countries mentioned.

In this article, therefore, a number of so-called accidental poisonings in adults will be included as accidental, although very often in fact they have been instances of attempted suicide or self-poisoning (Kessel, 1965) and in no way mischance. Selfpoisoning is the main cause of the marked rise of poisoning in adults which has occurred over the past 20 years. Fig. 2 shows the steady rise in admissions of poisoned patients to the Poisoning Treatment Centre of the Edinburgh Royal Infirmary. This is therefore a major epidemic. Eighty per cent of the 812 patients admitted last year were suffering from self-poisoning, $10 \%$ were truly suicidal, and only $10 \%$ genuinely accidental. Self-poisoning is most frequent in the early twenties, and this is three times more common in young females than in young males. In the older age groups the incidence is the same for both sexes (Fig. 3).

\footnotetext{
* Consultant Physician, Poisoning Treatment Centre, Royal Infirmary, Edinburgh ; Director, Scottish Poisons Information Bureau.
}

\section{Poisoning in Children}

In most children incidents of poisoning are accidental, but it is not uncommon in Scandinavia for children aged 11 to 15 to indulge in self-poisoning. Britain tends to follow Scandinavia in the pattern of self-poisoning, and there is evidence that even in the younger groups accidental poisoning is on occasion not in fact mischance but a pattern of purposeful behaviour. This should be suspected, especially when several episodes of poisoning occur in the one child. Another important aspect of the problem is therapeutic poisoning, which occurs in infants and toddlers, particularly with salicylates.

However these episodes are classified-self-poisoning, attempted suicide, genuine suicide, accidental, deliberate, or therapeutic poisoning-an outstanding factor in the rising incidence is the availability of medicaments and household preparations. It is important, therefore, to consider how this danger can be lessened or prevented.

In children the hackneyed advice regarding the locking up of all medicines cannot be too of ten repeated. Iron tablets and salicylates remain the commonest forms taken; but this is simply a matter of ready availability and not necessarily choice on the child's part. Judging from the number of inquiries from the National Poisons Information Service contraceptive pills are probably the third most common medicaments accidentally taken by children. Children are often attracted by the colour of tablets and their resemblance to sweets, and this danger may be increased by harassed parents describing them as such to persuade the child to take medicine. This is a mistake which many a parent has lived to regret when later confronted with their child poisoned by "sweets."

In the prevention of accidental poisoning in children there is no alternative to the safely positioned, locked medicine cupboard. The family doctor should regard it as part of his contract in looking after a family to attend to the medicine cupboard, and also ensure that household preparations, such as bleach, are removed from their time-honoured, readily getat-able site beneath the sink.

Children, especially toddlers, are very susceptible to the toxic effects of salicylates. These may occur even with modest doses 
which until recently have been regarded as safe (Craig et al., 1966). The danger is increased considerably in the dehydrated febrile child. If therapeutic poisoning is to be avoided the easily remembered and well-established dosage schedule of 1 to $1 \frac{1}{2}$ grains of salicylate per pound of body weight $(0.12$ to 0.18 g. $/$ kg.) per day should not be applied to infants and toddlers. This dosage schedule was designed for older children being treated under close supervision in hospital for rheumatic fever. Outside hospital, where it may be difficult to maintain an adequate fluid intake in infants and toddlers, the dose of salicylate should be no more than $1 \mathrm{gr}$. $(60 \mathrm{mg}$.) per year of life, five times a day and for no longer than two days at the maximum dosage.

\section{Poisoning in Adults}

In adults also, availability of medicaments is an important factor. There is no doubt that the prescription of barbiturates, tranquillizers, and antidepressive drugs has certainly prevented large numbers of patients from indulging in self-poisoning or suicidal poisoning. The obvious difficulty in prescribing these
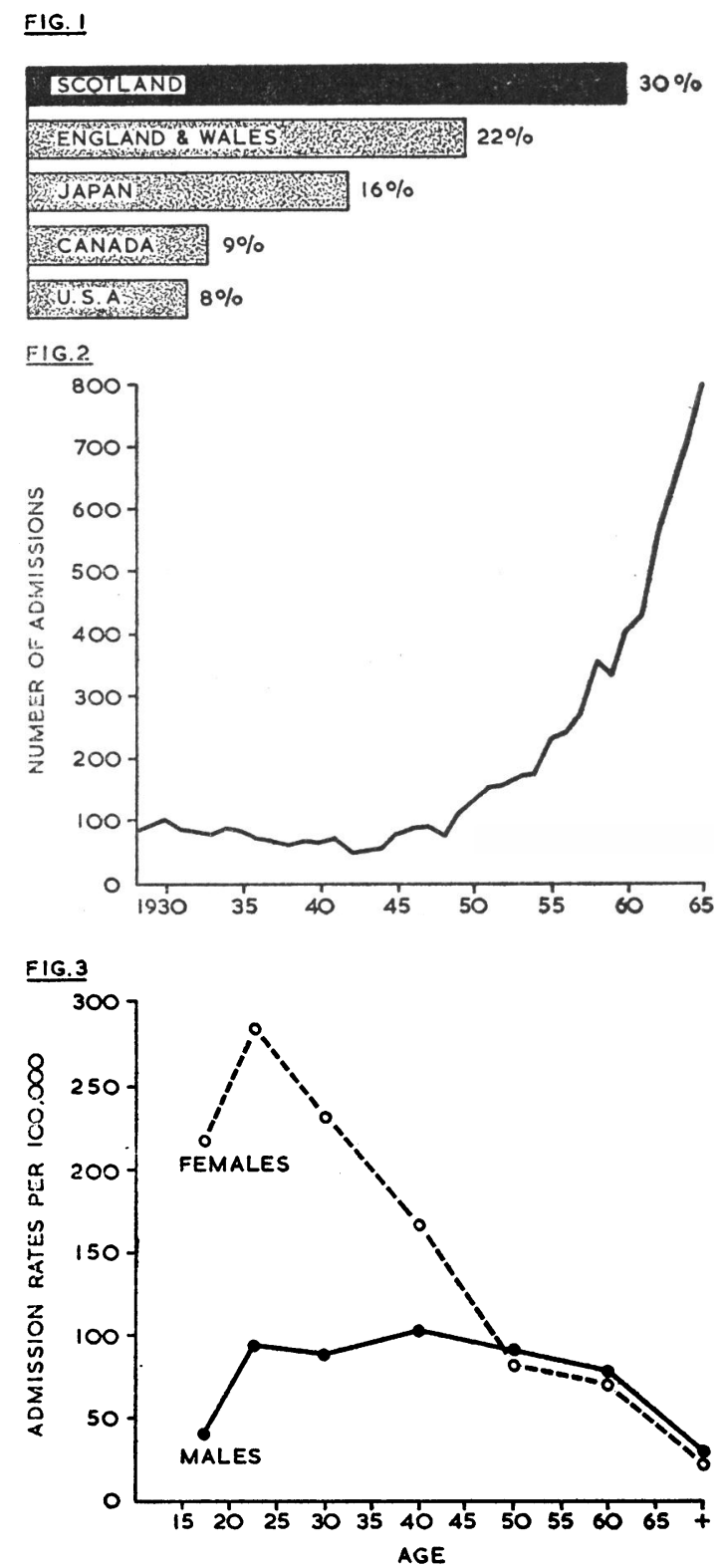

Frg. 1.-Percentage of fatal domestic accidents due to poisoning and gassing FIG. 2.- Yearly admissions of poisoned patients, Royal Infirmary of Edinburgh, 1928-65. FIG. 3.-Self-poisoning : one-year admission rates per 100,000 by age and sex. Edinburgh adults only. drugs is that, while affording him sleep, sedation, or relief of depression, at the same time the means of rendering himself unconscious or killing himself are being placed in his hands. It should always be explained to a depressed patient that there will be a delay after starting treatment before benefit is achieved from antidepressant drugs. Also because of this delay the general practitioner should always carefully consider the need for expert psychiatric advice before he himself undertakes antidepressive therapy. The prescription of a large number of barbiturate tablets to a patient suffering from insomnia without endeavouring to determine whether the insomnia is a symptom of depression is tantamount to granting the patient a licence to paison himself. With the increasing frequency of self-poisoning it is vital to take the utmost care and diligence in the prescription of these drugs.

Another important factor in the ready availability of drugs is that hoarding of drugs, either wilfully or thoughtlessly, is very common. In Great Britain today almost every household medicine cupboard contains a potentially lethal supply of drugs. When the sleeping-tablet is changed or another antidepressant drug tried, is it known how many of the original prescription are left? After an illness is the doctor aware what remains in the home medicine cupboard? As self-poisoning is so often an impulsive act the careful doctor will from time to time examine the medicine cupboard and remove all dangerous drugs that are not currently required.

It is a frequent practice for supplies of sleeping-tablets to be left by the bedside. Patients are often found to have taken an overdose in these circumstances. These episodes are usually called accidental poisoning, the explanation being that the patient, having taken his usual dose, may become confused and repeat the dose several times. It is much more likely, however, that these are acts of self-poisoning or even suicide, a possibility which the doctor does not always consider. Whatever they may be it is best that tablets should be left in the medicine cupboard and not at the bedside.

The profession is constantly being encouraged by vested interests to prescribe the latest safe non-barbiturate hypnotic. The cautious doctor will realize that only experience will show just how safe these drugs really are. Overdosage, for example, by glutethamide or methaqualone often presents a complex clinical picture, and those experienced in treating such patients often find the management more difficult than barbiturate poisoning and a successful outcome more uncertain.

In some countries certain tablets incorporate ipecacuanha as a safety measure in the event of overdosage. This is a most undesirable practice, partly because the quantity of ipecac. required to ensure emesis in overdosage would be considerable : also when ipecac. is incorporated with certain sedatives and tranquillizers which themselves have an antiemetic effect emesis might not occur and the ipecac. might then give rise to poisoning by virtue of absorption of its emetine content. Furthermore, if the ipecac. should produce emesis in a semiconscious patient then he is exposed to all the dangers, including sudden death, from aspiration of vomit.

Despite salicylate being the choice of physically healthy young people who indulge in self-poisoning or suicidal poisoning, the mortality rate is higher than that from barbiturates. There can be no question of making salicylates available only on prescription, but certain measures regarding their sale should be introduced. It seems wrong that in this competitive age one way of keeping ahead of the Joneses is to have a bigger bottle of salicylate in the house. Such, however, is the persuasion of certain manufacturers. In public-houses and grocers' shops salicylates should be available for sale only in small amounts, such as 10 tablets. In chemists, larger amounts, up to 50 tablets, might be sold at any one time, but the pharmacist should exercise discretion in supplying even these amounts, especially to young girls. 
Now that potent remedies are available and it is no longer necessary to practise mystic, the marking of a prescription "N.P." should be the rule rather than the exception. While accepting that patients may sometimes change their tablets from one container to another, knowledge of the identity of the contents on occasion saves valuable time and may be very helpful in the treatment of overdosage.

\section{Doctors' Responsibility}

In adults factors other than availability require consideration in self-poisoning, attempted suicide, and true suicidal poisoning. Self-poisoning, defined as a conscious, impulsive, manipulative act, undertaken to secure redress of an intolerable situation, occurs most often in depressed or anxious persons and it is also a feature of adolescent behavioural disorders and in people who have no psychiatric illness but are simply distressed. It frequently represents an unstated appeal for help. Causes of self-poisoning include marital disharmony, a broken home in childhood, and problems regarding alcoholism and poverty. Its prevention depends on an appreciation and management of these underlying problems. This may involve an adjustment of environment and an improvement of bad social circumstances. In particular, the practitioner must be on the look-out for strains within a family group. Most practitioners are aware that agitated, anxious, or depressed patients are exposed to the risk of selfpoisoning or even suicide. It is impossible to assess how of ten preventive efforts by the doctor have been successful, but there must, however, be many occasions when the physician, aware of the dangers, is reluctant to act. Most doctors find difficulty in questioning their patients on the subject of suicide, and patients are averse to broach the subject unless encouraged to discuss it. Only by overcoming this hesitancy can doctors anticipate the possible outcome of certain family situations, distress, anxiety, and depression, and take appropriate preventive measures.

Doctors therefore have considerable responsibility in the prevention of "accidental" poisoning by medicaments. Prescription of smaller amounts of dangerous drugs and the marking of prescriptions N.P., although important, do not absolve them from further responsibility. The practice of preventive medicine requires that every doctor should extend his orbit from the protection of the toddler by insisting on a properly locked medicine cupboard, through the early recognition of the domestic stresses in the young married couple, to an urgent awareness of the dangers of poisoning in the depressed, agitated, or even distressed adult. He should resist the temptation to prescribe a "new safe" hypnotic unless he is satisfied that there is no well-tried effective alternative. $\mathrm{He}$ should take precautions to prevent the home medicine cupboard, albeit locked, from being filled with lethal drugs available to satisfy the impulsive behaviour of the selfpoisoner. These measures should not be regarded as belonging to the province of the perfectionist. Good medicine demands that they should be practised by all.

\section{REFERENCES}

Backett, E. M. (1965). Domestic Accidents. W.H.O., Geneva.

Craig, J. O., Ferguson, I. C., and Syme, J. (1966). Brit. med. F., 1, 757. Kessel, N. (1965). Ibid., 2, 1265.

\title{
Industrial Health of Youth
}

\author{
R. C. BROWNE,* D.M., F.R.C.P.
}

Brit. med. F., 1966, 2, 790-792

The health and safety of young people at work are part of the much wider problem of industrial health and safety in general. It is divided between parents, school, and industry, and on the medical side between the personal doctor, the school health service, the appointed factory doctor, the industrial medical officer (if any), and the medical inspector of factories. Moreover, within industry itself this responsibility may be further subdivided between the technical management, the apprenticeship and training scheme, the personnel department, and the safety officer. There is therefore tremendous fragmentation of responsibility, which contains all sorts of incoordinate gaps, often haphazardly bridged only by the young persons themselves.

Nowadays homes are more dangerous places than most modern factories, and roads and streets are very much more so. Home training, therefore, to avoid falls, burns, and cuts, and to take reasonable care, is the first and most important step in implanting in the child's mind the idea of safe working practice upon which future industrial safety is based. After the home the next most important influence for care could be the mothercraft class of the girls' school. Care in industry is directly derived from care in the use of knife and fork, the handling of hot liquids and matches, how to lift, how to use a pair of steps, the danger of pinched fingers, and of not allowing play round doors. The most important danger of fires needs to be understood. If mother understands and imparts all this by practice and precept, the first steps in safe working habits in the subsequent employment of her children in industry have already been taken.

\section{Safety-A Habit}

Real safety is a habit, a conditioned reflex built into the way things are done automatically and unconsciously. It is an integral part of technical working practice, not really a matter of campaigns, posters, and ballyhoo. True safety is good training supported and intensified by repeated careful practice, thus augmenting rather than extinguishing the conditioned reflex of care which has been set up. As yet, this is by no means fully understood by industry in general, in which there is a tendency to think of safety as something of secondary importance to be administered by an officer of secondary ability. Suppose that in hospitals we had a National Health Service safety officer (non-medical of course-cheaper this way!) 